\title{
Vitamin A Induced Benign Intracranial Hypertension
}

\author{
ROBERT VOLLBRACHT, AND JOHN GILROY
}

SUMMARY: A case of benign intracranial hypertension due to prolonged administration of a low dose of Vitamin $A$ is described in a young male investigated as a brain tumor suspect. Computerized axial tomography showed small and symmetrical lateral ventricles which was consistent with the diagnosis. The syndrome of benign intracranial hypertension and its relationship to chronic Vitamin $A$ toxicity is discussed.

RÉSUME: Un cas d'hypertension intracrânienne bénigne dûe à l'administration prolongée d'une petite dose de vitamine A est décrit chez un jeune homme chez qui on suspectait la présence d'une tumeur cérébrale. Une tomographie axiale montra des petits ventricules symétriques compatibles avec le diagnostic. Le syndrome d'hypertension intracrânienne bénigne et sa relation avec la toxicité de la vitamine $A$ est discuté.

From the Department of Neurology, Wayne State University, Detroit, Michigan 48201.

Reprint requests to Dr. John Gilroy, Wayne State University, School of Medicine, Department of Neurology, 3900 John R. Detroit, Michigan 48201 U.S.A.
The clinical syndrome of benign intracranial hypertension (pseudotumor cerebri) is characterized by an increase in intracranial pressure with papilledema in an otherwise healthy and alert individual. It usually resolves spontaneously and recurrence is rare.

The majority of cases of benign intracranial hypertension occur in women between the ages of 14 and 40 and it has been reported following the menarche in obese adolescent females, during early pregnancy, following abortion, and in obese women in their 30's with menstrual irregularities. The common factor in these cases seems to be an unidentified hormonal imbalance and the course may be protracted in older patients with menstrual problems. A number of other unusual factors have been recognized in this syndrome, including chronic Vitamin A toxicity (Weisberg, 1975).

The onset is usually abrupt with the development of headache. Examination shows evidence of increased intracranial pressure with papilledema which is bilateral and symmetrical. The patient may experience episodes of transient blurring of vision and diplopia owing to a sixth nerve palsy. These symptoms, however, are non-specific manifestations of increased intracranial pressure. Visual field testing may reveal an enlarged blind spot and/or a binasal inferior quadrant defect (Dersh and Schlezinger, 1959), which is probably due to interstitial edema affecting the nerve fibers supplying the affected region of the retina. Patients frequently complain of nausea but vomiting is unusual. The neurological examination is normal except for the papilledema and the occasional occurence of sixth nerve palsy and visual field defects.
The diagnosis of benign intracranial hypertension is usually suggested by the history, but the possibility of a brain tumor has to be excluded in all patients. Until recently, evaluation required pneumoencephalography which showed small symmetrical lateral ventricles without displacement. This study has been superceded by computerized axial tomography (Baker et al., 1975), which is a new neuroradiological technique providing crosssectional views of the cerebral hemispheres including the size and shape of the ventrical system. This technique is replacing pneumoencephalography in most cases in the diagnosis of intracranial abnormalities.

\section{CASE REPORT}

An 18 year old, white male was seen in the Department of Neurology, Wayne State University, complaining that he had a sensation of "being pushed forward by some unknown force" for about 6 months. The patient also noticed some difficulty with equilibrium and a tendency to lean toward one side or the other without actually falling. These episodes had been increasing in frequency during the week prior to examination.

The patient denied headache, vertigo, loss of consciousness, or seizures. There was no history of diplopia, nausea, vomiting or other neurological symptoms.

The past medical history was unremarkable. He had been seen by his family physician 4 years previously, at which time his physical examination, including funduscopic examination, was normal.

The patient had acne for which he had been taking 10,000 to 20,000 International units of Vitamin A every day for more than 2 years. 
General physical examination on admission revealed a thin but well developed white male in no acute distress. The vital signs were normal. Significant physical findings were acne bilaterally on face and thighs and bilateral papilledema.

Neurological examination revealed an alert, intelligent, cooperative patient who was oriented to person, place and time, and had no defects in mentation, speech or memory. The funduscopic examination revealed bilateral papilledema, and visual field testing was normal. The pupils were equal, round and reacted to light briskly, and the extraocular movements were full without nystagmus or ptosis. The gait was normal. There was no difficulty with walking on heels, toes or in tandem gait. Tests of coordination were well performed. Strength was normal and equal bilaterally in all muscle groups. The reflexes were normal and symmetrical and there were bilateral plantar flexor responses.

The laboratory tests, which included a hematocrit, hemoglobin, white blood cell count, BUN, fasting glucose, urinalysis, VDRL, SGOT, SGPT, bilirubin, calcium, electrolytes, and creatinine, were all within normal limits. Chest and skull $x$-rays were normal.

The electroencephalogram showed slowing bilaterally and symmetrically with intermittent theta activity in the temporal and occipital regions. A radioisotope brain scan was normal. Computerized axial tomography showed a very small third ventrical and small lateral ventricles. The pineal was in the midline.

Vitamin A was discontinued on admission but a Vitamin A level drawn 2 weeks after admission was elevated at 115 units (normal 40-100).

The patient was treated with corticosteroid therapy using dexamethasone $16 \mathrm{mg}$ per day in divided doses for 10 days, then Prednisone $40 \mathrm{mg}$ in divided doses daily. The corticosteroids were gradually reduced over a period of several weeks.

The papilledema had diminished to a marked degree over a period of several weeks. The patient was symptom-free 2 months after the withdrawal of Vitamin A.

\section{DISCUSSION}

Vitamin A toxicity was first described in Arctic explorers who developed acute vertigo and headache following a meal of polar bear liver, which is known to have a high content of Vitamin A. The symptoms associated with acute Vitamin A toxicity include frontal headache, nausea, vomiting, vertigo, drowsiness and irritability (Feldman and Schlezinger, 1970).

High doses of Vitamin A have been utilized for a number of reasons, such as the prevention of acne, prophylaxis against the common cold, keratosis folliculosis, and food faddism. Chronic Vitamin A toxicity has been described in adults taking doses of Vitamin A ranging from 25,000 to $600,000 \mathrm{IU} /$ day for a duration of 2-8 months (Muenter et al., 1971; Edmunds et al., 1973). The case reported here demonstrates that increased intracranial pressure may occur following the chronic use of smaller doses of Vitamin A.

The clinical presentation of chronic Vitamin A intoxication (Muenter et al., 1971) includes dermatitis with dryness, maculopapular eruptions, pigmentation and pruritis. There may be hair loss, generalized weakness and fatigue and anorexia and pain in the bones and joints. Impairment of liver function has been reported and may be associated with hepatomegaly and splenomegaly. Muscle stiffness increasing with exertion and psychiatric disorders such as severe depression or schizophrenic-like picture have been described with resolution of symptoms following withdrawal of Vitamin A (DiBenedetto, 1967). There are also reports of mild anemia, increased sedimentation rates, decreased serum albumen levels and demineralization of bone in some cases. However, the case presented here illustrates that benign intracranial hypertension may occur in chronic Vitamin A intoxication without other clinical abnormalities.

The pathogenesis of benign intracranial hypertension in Vitamin A to- xicity is not known. It is possible that it is associated with cerebral edema, or is the result of increased formation and/or decreased absorption of the cerebrospinal fluid.

Radiological studies are usually normal and the electroencephalogram may be normal or show a diffuse symmetrical slowing in the theta range over both hemispheres compatible with increased intracranial pressure. The final diagnostic procedure using pneumoencephalography or more recently computerized axial tomography shows small slit-like ventricle consistent with cerebral edema and increased intracranial pressure.

In a few long standing cases, skull $x$-ray may show enlargement of the sella turcica with erosion of the posterior clinoid processes or demineralization of the lamina of the dorsum sella. Pneumoencephalography may show excess air within the sella turcica in such cases, which has been called "the empty sella syndrome." This is not usually associated with hypopituitarism (Weisberg, 1975).

Most cases of benign intracranial hypertension show spontaneous remission without treatment. In the more severe cases with disabling headaches or impairment of visual acuity, treatment has included repeated lumbar puncture, diuretics, glycerol and corticosteroids. The use of corticosteroids including Prednisone $20.50 \mathrm{mg}$ daily or dexamethasone 6-12 mg daily appears to give the most consistent results with a good response within one week in the majority of cases (Weisberg, 1975). Surgical treatment has been recommended for the rare refractory case with a progressive loss of visual acuity. Treatment in such cases includes subtemporal decompression (Wilson and Gardner, 1966), ventriculo-atrial or ventriculoperitoneal shunting (Jackson and Snodgrass, 1955), and bilateral orbital optic nerve decompression (Galbraith and Sullivan, 1973).

\section{CONCLUSION}

A case of benign intracranial hypertension due to Vitamin A intoxication was seen in a young male 
who was admitted to the hospital and investigated as a brain tumor suspect. Computerized axial tomography showed no intracranial abnormality and that the lateral ventricles were small and symmetrical, a condition which is consistent with a diagnosis of benign intracranial hypertension. The condition resolved following withdrawal of Vitamin A. This case indicates that suspected benign intracranial hypertension may be investigated with 1) skull x-ray; 2) electroencephalography; 3) lumbar puncture; and 4) computerized axial tomography. If the clinical picture is compatible with a diagnosis of benign intracranial hypertension and the results of these tests are consistent with this diagnosis, further evaluation may not be necessary. The patient should, however, be followed at frequent intervals as an outpatient until the condition resolves.

\section{REFERENCES}

BAKER, H. L. Jr., HOUSER, O. W. et al. (1975). Computerized Tomography of the Head. J. A. M. A. 233: 1304-1308.

DERSH, J. and SCHLEZINGER, N. S. (1959) Inferior Nasal Quadrantanopsia in Pseudotumor Cerebri. Trans. Amer. Neurol. Assoc. 84: 116-118.

DiBENEDETTO, R. J. (1967). Chronic Hypervitaminosis in an Adult. J. A. M. A. 201: 700-702.

EDMUNDS, C., BEHRENS, M., et al. (1973). Pseudotumor Cerebri and Low Vitamin A Intake. J. A. M. A. 226: 674.
FELDMAN, M. H. and SCHLEZINGER, N. S. (1970). Benign Intracranial Hypertension Associated with Hypervitaminosis A. Arch. Neurol. 22: 1-7.

GALBRAITH, J. and SULLIVAN, J. H. (1973). Decompression of the Perioptic Meninges for Relief of Papilledema. Am. J. Ophth. 76: 687-692.

JACKSON, I. J. and SNODGRASS, S. R. (1955). Peritoneal Shunts in Treatment of Hydrocephalus and Increased Intracranial Pressure. J. Neurosurg. 12: 216-222.

MUENTER, M. D., PERRY, H. O. and LUDWIG, J. (1971). Chronic Vitamin A Intoxication in Adults. Am. J. Med. 50: 129-136.

WEISBERG, L. A. ( 1975). Benign Intracranial Hypertension. Medicine. 54: 197-207.

WILSON, D. H. and GARDNER, W. J. (1966). Benign Intracranial Hypertension with Particular Reference to its Occurance in Fat Young Women. Canad. Med. Assoc. J. 95: 102-105. 